\title{
Control of a Photovoltaic-battery grid-connected multi-source system under different operating conditions
}

\author{
Siham Chakiri ${ }^{*}$, and My Tahar Lamchich ${ }^{2}$ \\ ${ }^{1}$ Computer Science Department, cadi Ayyad University-FSTG, Marrakesh, Morocco \\ ${ }^{2}$ Computer Science Department, cadi Ayyad University-FSTG, Marrakesh, Morocco
}

\begin{abstract}
This paper deals with the control of a grid-connected multi-source power system based on a photovoltaic (PV) array and a battery energy storage system (ESS), taking into account the variable and intermittent characteristics of the solar irradiation level and the ambient temperature in Morocco. The PV generator is connected via a dc-dc boost converter to a common dc bus which is connected through a bidirectional dc-dc converter to the battery ESS. The dc bus output is connected to the mains via a PWM dc-ac converter with an LCL filter. The control technique consists of three parts: the PV array is considered as the primary source and the boost converter is controlled locally to generate the maximum power extraction (MPPT), while the bidirectional dc-dc converter of the ESS battery is controlled to ensure the energy balance according to the power flow under different solar irradiation and temperature conditions. The PWM inverter is controlled to regulate the DC bus voltage and maintain the power factor at the unit. The system is implemented in Matlab/Simulink environment. The effectiveness of the control strategy is carried out by simulation results.
\end{abstract}

\section{Introduction}

Recently, grid-connected distributed generation (DG) based on renewable energy sources (RES) has received significant attention worldwide due to their drivers related to decreasing dependence on conventional fossil fuels resources, reducing greenhouse gas emissions and meeting the growing demand for energy. Among the various RES, photovoltaic (PV) generation is increasingly used and plays a very important role, especially in developing countries. With a high level of radiation with an average value of about $5 \mathrm{KWh} / \mathrm{m}^{2} /$ day and an illumination hours of more than 3000 hours/year, Morocco does not escape this trend, an energy policy has been launched since 2009 and was accelerated, in December 2015, at the COP21 in Paris, aiming to increase the share of renewable energy up to $52 \%$ by 2030 [1] corresponding to an installed renewable capacity of $13000 \mathrm{MW}$ which would limit the need of fossil fuels, reduce energy dependence to less than $82 \%$ [2].

Combined with the energy storage system (ESS) as stable energy source, the multi-source system are proposed to facilitate the connection of RES to MV distribution grid. Thus, by selecting the advantages of each RES and/or ESS, the multi-source system concept maximizes efficiency, reliability and ensures the provision of energy without intermittency compared to systems comprising only one RES. Amount the major types of batteries, Lithium-Ion battery with high storage capacity, charge possibility at several times a day, absence of memory effect, long life cycle, low maintenance, less toxic than other models, high energy density is considered a promising device but, high cost, high risk of damage overload, self-discharges and risk of explosion if there is no adequate control of the temperature are the main disadvantages of this technology [3-5].

The power electronics devices dominate in multi-source system as a DG interface [6]. The direct current from the $\mathrm{PV}$ panels has to be converted into alternating current using DC-DC booster and DC-AC inverter in order to connect to an AC grid. Therefore, appropriate control techniques have to be developed to achieve the objectives of a grid connected multi-sources. Since control and operation of a multi-source system is more complicated, this research work focuses on the control of DC-DC-AC converters interfaced with a multi-source system connected to the grid through an LCL filter and different modes of operation have been studied. The control schemes among various converters have been proposed to harness maximum power from RES and to maintain the stable operation of the system under the real Moroccan variable climate change.

The rest of this document is organized as follows: firstly section II presents the architecture of the proposed multi-source system, section III is focused on the modeling of the multi-source system components. Section IV deals with system control and energy management. Section V presents simulation results and conclusions are presented in section VI.

\footnotetext{
* Corresponding author: siham.chakiri@gmail.com
} 


\section{Proposed system configuration}

The multisource system components could be connected in various ways, depending on the proposed power electronics topology. One option is to connect the sources with the grid via an ac bus link, using an inverter for every source. This will increase the redundancy of the system, as every source can work independently from the other sources. However, this will increase the overall system cost. Another option, which is proposed in this study, is to connect the sources to a common dc bus link. Subsequently, an inverter will be used to connect to the grid. This method is less costly and easier to control. Figure 1 shows the architecture of the considered grid connected multi-sources system under study in this work. The primary energy sources for the system is PV generators, while the lithium-ion battery bank works as an energy storage backup source. The system is intended to be grid-connected applications and it is modelled using Simulink/Matlab to simulate the operations and control of the system. PV panels are connected to the dc bus via A DC-DC boost converter controlled to extract Maximum Power Point Tracking (MPPT). The batteries bank is connected to the same DC bus through a DC-DC bidirectional converter controlled to manage the power generation between RES and grid in different conditions and to follow the reference of charge or discharge current and to regulate the DC bus voltage. The whole multi-sources power system is connected to the grid through a three phase DC-AC inverter with an LCL filter.

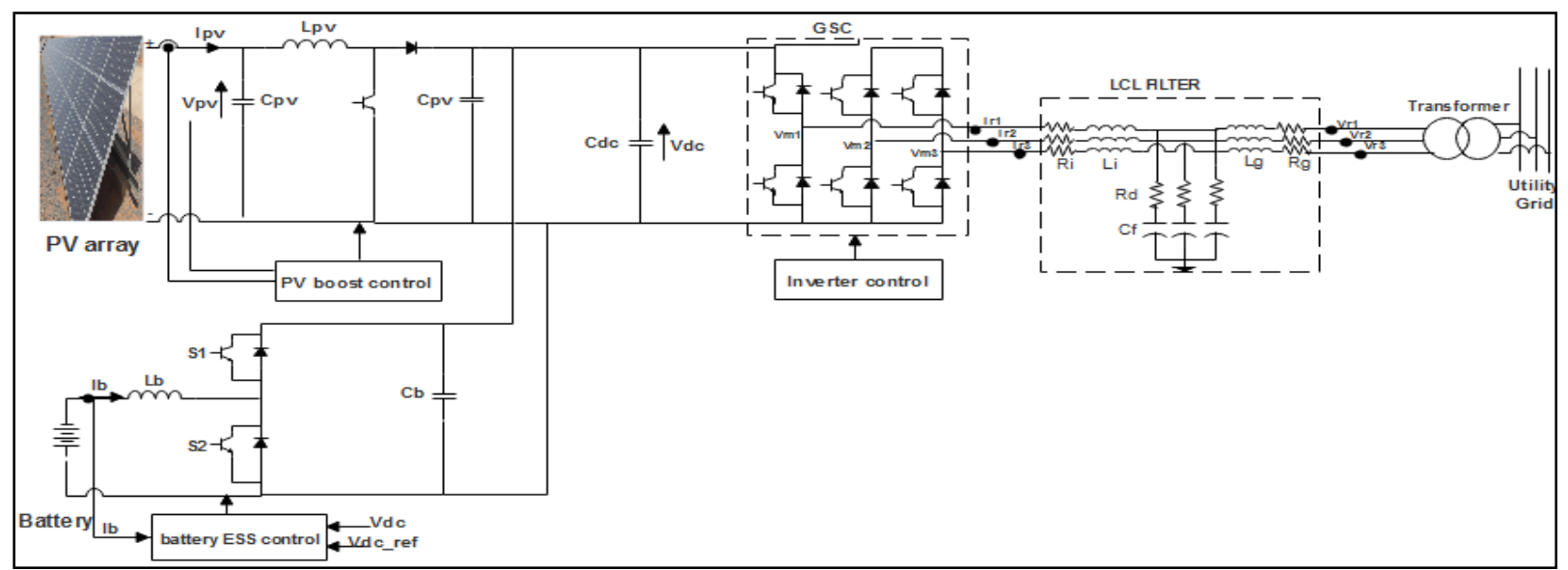

Fig. 1. Topology of Grid-connected multi-source system based on PV panel with battery energy storage.

\section{Modeling of multi-sources system}

\subsection{Modeling of PV Panel}

In order to study the behaviour of solar cells, different models have been developed. To reduce the number of equations to be solved and simplify the equivalent circuit, the simple diode solar cell model as shown in Figure 2 is adopted [7, 8]. In the absence of solar radiation, the solar cell's behaviour is a diode and can be represented by the Shockley equation given as (1):

$$
I_{d}=I_{s}\left(e^{\left(\frac{V_{P V}}{V_{T}}\right)}-1\right)
$$

Where $I_{S}=$ Reverse current $(\mathrm{A})$ and $V_{T}=$ Thermal voltage given by equation (2)

$$
V_{T}=\frac{K x A x T_{c k}}{q}
$$

When the PV cell is ideal it is sufficient to be modelled with a parallel source current with a diode. The current source represent the intensity of solar radiation and the diode represents the behaviour of $p-n$ junction. The basic equation in semiconductor theory that mathematically describes the I-V characteristic of the ideal PV cell is (3):

$$
I_{P V}=I_{P H}-I_{d}=I_{P H}-I_{S}\left(\boldsymbol{e}^{\left(\frac{V_{P V}}{V_{T}}\right)}-\mathbf{1}\right)
$$

Where $I_{P H}=$ Photo generated current (A)

A serie $\left(R_{s}\right)$ and parallel $\left(R_{p}\right)$ resistances are inserted in the ideal model of solar cell. $\mathrm{R}_{\mathrm{s}}$ Reflects to the losses caused by the resistance of the material and connections while $R_{p}$ introduce the effect of leakage current [9]. Generally, the serie resistance $R_{s}$ value is very small, whereas $R_{p}$ has a very high value and it can be ignored. The output relation of the current becomes (4):

$$
I_{P V}=I_{P H}-I_{S}\left(\boldsymbol{e}^{\left(\frac{V_{P V}+R_{S} x I_{P V}}{V_{T}}\right)}-\mathbf{1}\right)-\frac{V_{P V}+R_{S} x I_{P V}}{R_{p}}
$$

A PV module is made by connecting $\mathrm{N}$ cells in series and parallel. The connection of cells in series increases the voltage while connecting them in parallel increases the output current. A panel with the cells connected in series can be described by Equation (4) by adding the number of cells $\mathrm{N}$ to the relation (2) of $\boldsymbol{V}_{\boldsymbol{T}}$ as follows (5):

$$
V_{T}=\frac{N x K x A x T_{c k}}{q}
$$

The PV array is a serial/parallel association of $\mathrm{N}_{\mathrm{s}} / \mathrm{N}_{\mathrm{p}}$ elementary modules to increase voltage or overall current, if all the cells are identical and operate under the same conditions the electrical model of the PV array based on the single diode model is given by the following equation (6): 


$$
\begin{aligned}
& I_{P V}=N_{p} x I_{P H}-N_{p} x I_{S}\left(e^{\frac{1}{V_{T}}\left(\frac{V_{P V}}{N_{S}}+\frac{R_{S} x I_{P V}}{N_{p}}\right)}-\mathbf{1}\right)- \\
& \frac{N_{P}}{R_{S}}\left(\frac{V_{P V}}{N_{S}}+\frac{R_{S} x I_{P V}}{R_{p}}\right)
\end{aligned}
$$

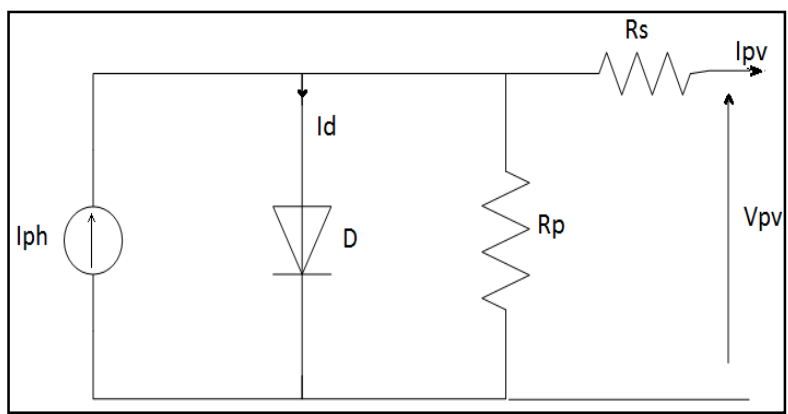

Fig.2. One diode equivalent circuit of a solar cell.

\subsection{Modeling of battery}

The equivalent diagram of the battery electric model is composed of a controllable voltage source with an internal resistance. The state of charge of the battery "SOC" is defined by the following equation [10]:

$$
\text { SOC }=100\left(1-\frac{1}{Q} \int \mathrm{i}_{b}(t) d t\right)
$$

Where: $\mathrm{i}_{\mathrm{b}}$ is the battery current (A) and Q is the battery maximum capacity (Ah).

\section{Modeling of multi-sources system}

From the general topology of the multi-source system based PV panel with battery in Figure 1, three types of power converters are used. These converters must be controlled in a coordinated manner with the electrical grid in order to provide high power quality, high efficiency and uninterrupted power supply under varying solar irradiation and temperature conditions. The detailed control algorithms for each converter are designed in this section.

\subsection{DC-DC boost converter control}

In grid-connected multi-source system, the control objective of the boost converter is to track the Maximum Power Point (MPPT) of the PV array by regulating its terminal voltage. To determine the reference value of the solar panel terminal, various MPPT techniques can be implemented. Perturbation and observation (P\&O) [11], incremental conductance [12], Hill climbing, fractional short circuit current and voltage and Neural Networks methods are the popular used in the MPPT controllers due to their easy implementation, simplicity and fast response [13]. The basic perturbation and observation ( $\mathrm{P} \& \mathrm{O})$ algorithm based on solar irradiation and temperature is implemented in this work to harness the maximum power according to Figure 3 .

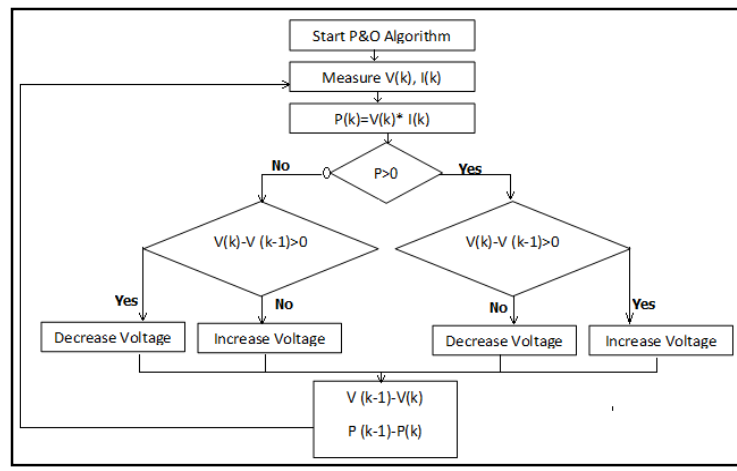

Fig.3. Flowchart for the Perturb and observe method to observe the maximum power [11].

\subsection{DC-DC bidirectional converter control}

The control strategy of the bidirectional converter (Figure 4) permit it to adjust the dc bus voltage at its fixed reference. A buck converter is used to the charging mode to store the excess energy and a Boost converter is dedicated to discharging mode where there is a deficit to provide energy demand. PI controllers are used to control the battery converter. Figure 5 shows the control diagram of buck-boost converter.

- The energy supplied by the PV system has the priority in meeting the demand of the grid operator over that supplied by the battery system.

- When PV systems produce more energy than demand, the excess energy is used to charge the battery bank.

- If the total power generated by photovoltaic systems is less than the demand, the required power will be supplied by the battery system.

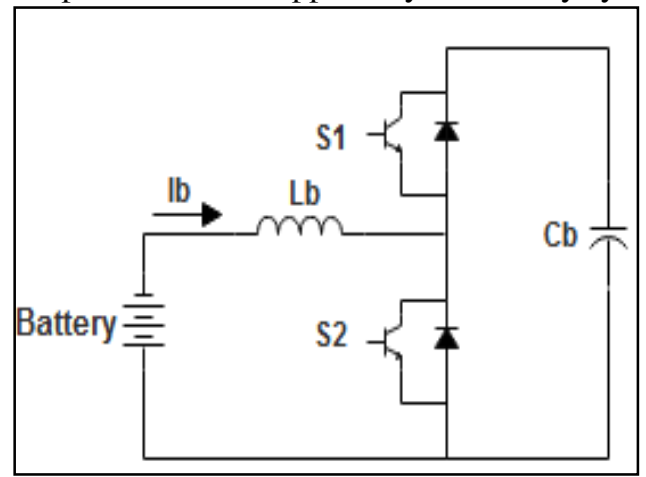

Fig 4. The bidirectional dc-dc converter

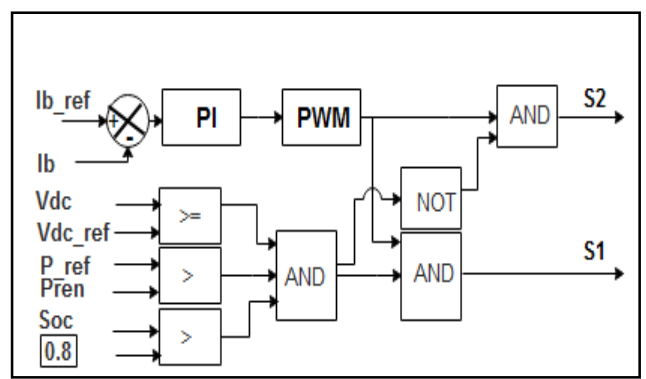

Fig. 5. Control scheme of battery DC-DC bidirectional 


\subsection{Grid side DC-AC inverter control}

The equations of voltage in grid side inverter in a rotating synchronous reference frame can be expressed as (8):

$$
\left\{\begin{array}{l}
v_{\mathrm{rd}}=v_{\mathrm{md}}-L \frac{\mathrm{d} i_{\mathrm{d}}}{\mathrm{dt}}-R i_{\mathrm{d}}+w L i_{\mathrm{q}} \\
v_{\mathrm{rd}}=v_{\mathrm{md}}-L \frac{\mathrm{d} i_{\mathrm{d}}}{\mathrm{dt}}-R i_{\mathrm{d}}+w L i_{\mathrm{q}}
\end{array}\right.
$$

Where $\boldsymbol{v}_{\text {rd }}$ and $\boldsymbol{v}_{\text {rq }}$ are the grid voltage components, $\mathrm{R}$ and $\mathrm{L}$ are the resistance and total inductance of the inductor, $\boldsymbol{v}_{\mathbf{m d}}$ and $\boldsymbol{v}_{\mathbf{m q}}$ are the inverter voltage components.

The grid side inverter is controlled using PI controllers to regulate the dc bus voltage via the direct component and reactive power to keep the power factor to unity by the quadrature component and two internal current control loop (direct and quadrature) as shown in Figure 6.

The output of the dc bus voltage regulation is the reference current for the current control loop which is compared to the inverter current to adjust its output current by PWM method.

A synchronization algorithm technique based on Phase Locked Loop (PLL) is used for grid connexion system. After the inverter PWM control, a LCL filter is connected to the inverter to reduce the high frequency harmonics.

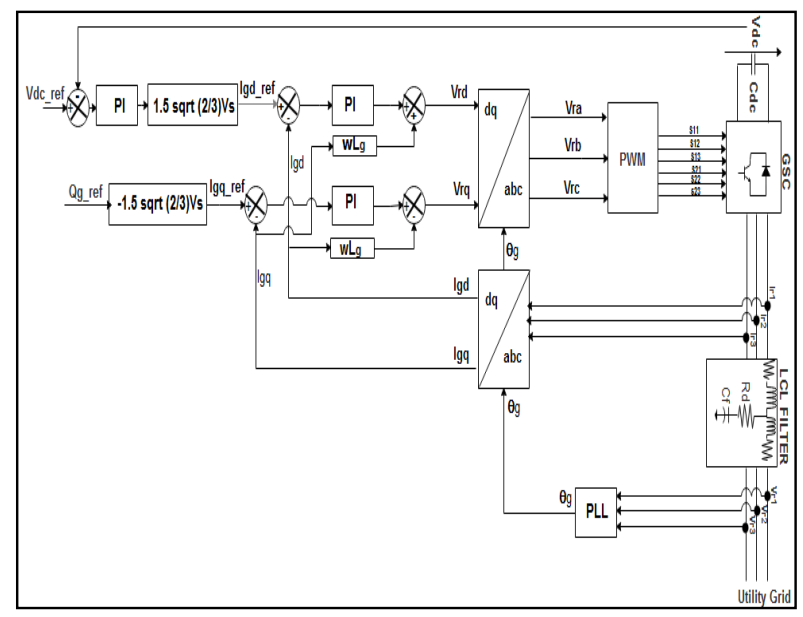

Fig.6. control scheme of inverter converter

\section{Simulation results}

The operation of grid connected multi-sources system (Figure 1) has been simulated in Matlab/Simulink environment as shown in Figure 7. The real Moroccan irradiation and temperature conditions used in simulation are presented in Figure 8 (a) and (b) respectively. Table 1 shows the using simulation parameters for grid-connected system.

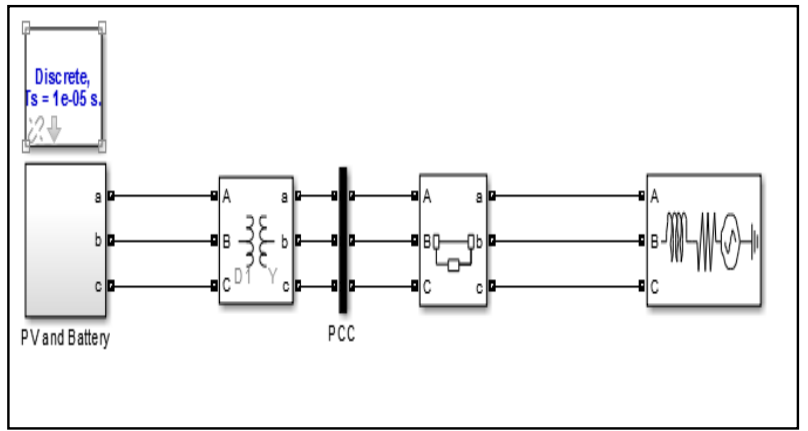

Fig. 7. Simulated Diagram of multi-source system based on PV and battery ESS

Table 3. Simulation parameters of the multi-source system.

\begin{tabular}{|c|c|}
\hline \multicolumn{2}{|l|}{ PV panel } \\
\hline Maximum power & $235 \mathrm{~W}$ \\
\hline Voltage at MPP & $30.3 \mathrm{~V}$ \\
\hline Current at MPP & $7.76 \mathrm{~A}$ \\
\hline Short circuit current & $8.49 \mathrm{~A}$ \\
\hline Open circuit voltage & $37.9 \mathrm{~V}$ \\
\hline Temperature coefficient of open $\mathrm{c}$ & $-130 \mathrm{mV} /{ }^{\circ} \mathrm{C}$ \\
\hline Temperature coefficient of short $\mathrm{c}$ & $+0.053 \% /{ }^{\circ} \mathrm{C}$ \\
\hline Temperature coefficient of power & $0.485 \% /{ }^{\circ} \mathrm{C}$ \\
\hline Number of cells in a PV module & 60 \\
\hline \multicolumn{2}{|l|}{ Battery ESS } \\
\hline Rated voltage $(\mathrm{V})$ & 560 \\
\hline Rated capacity (A/h) & 100 \\
\hline \multicolumn{2}{|l|}{$\mathbf{3}_{\varphi}$ grid, DC link } \\
\hline $\mathrm{Vg}(\mathrm{V})$ & 380 \\
\hline $\operatorname{Vdc}(\mathrm{V})$ & 560 \\
\hline
\end{tabular}

(a)

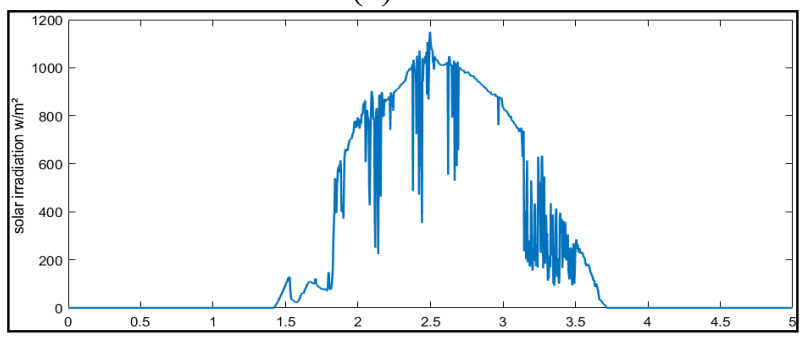

(b)

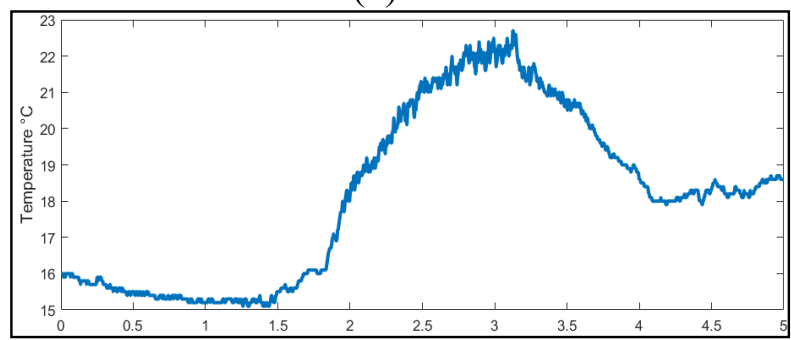

Fig.7. Irradiation (a) and temperature (b) profile of Morocco used for the simulation.

The voltages and the output power curves of the PV panel for different solar irradiations are shown in Figure 8 (a) and (b) respectively. The solar irradiation level is set low W/m from $0.0 \mathrm{~s}$ to $1.424 \mathrm{~s}$ and from $1.424 \mathrm{~s}$ to $5 \mathrm{~s}$, increases from $1.424 \mathrm{~s}$ to $3.71 \mathrm{~s}$. It can be seen that the $\mathrm{P} \& \mathrm{O}$ is continuously tracing the optimal voltage from $1.424 \mathrm{~s}$ to $3.71 \mathrm{~s}$. The algorithm only finds the optimal voltage at $2.424 \mathrm{~s}$ due to the slow tracing speed. It can be seen that the basic algorithm can correctly 
follow the change of solar irradiation. The output power closely follows the solar irradiation and ambient temperature change.

(a)

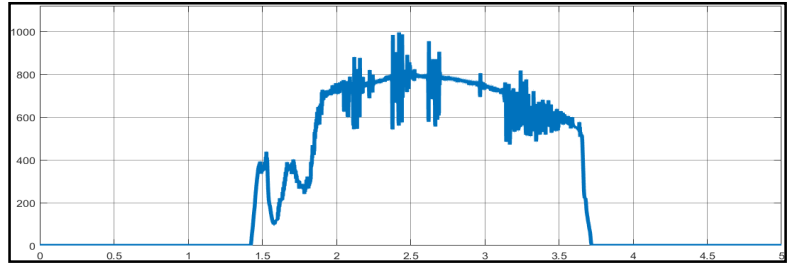

(b)

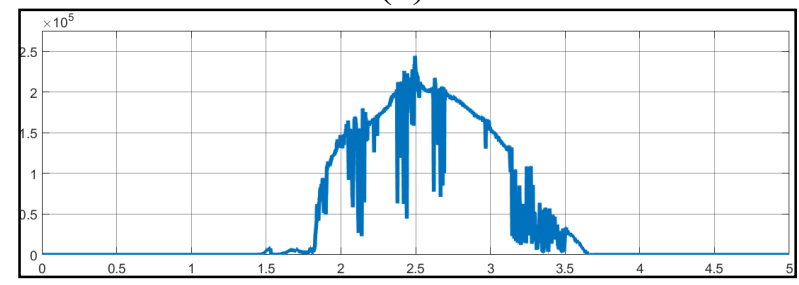

Fig.8. (a) The terminal voltage of the solar panel (b) and the output power of the PV.

Figure 9 represents dc bus voltage curve (a), direct (b) and quadrature (c) current and voltage (d).

The grid side converter shows that the measured direct and quadrature components of the grid current follow their references, and the dc bus voltage is maintained constant, these results demonstrate the dynamic performance of the controllers.

(a)

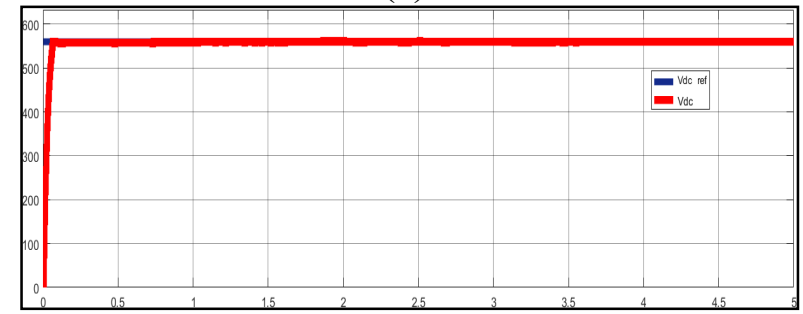

(b)

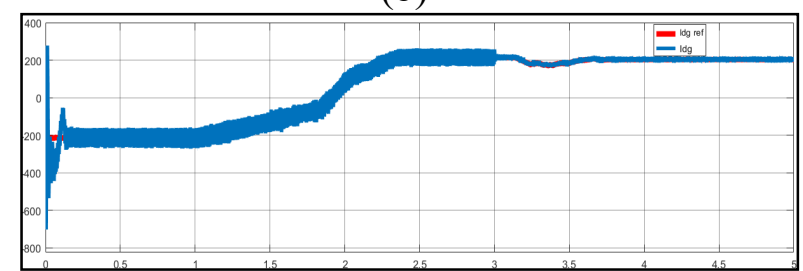

(c)

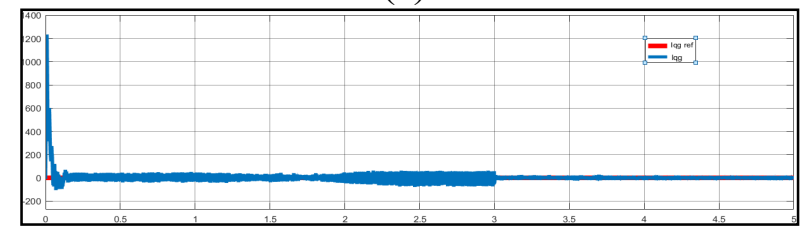

(d)

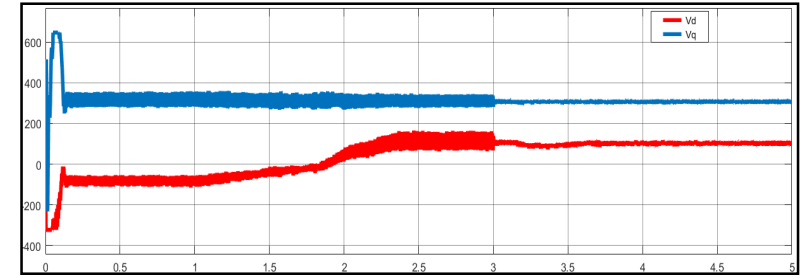

Fig. 9. (a) Dc bus voltage, (b) direct and (c) quadrature current and (d) voltage components.
Figure 10 shows the responses of voltage (a), current (b), active (c) and reactive (d) power on the grid side of the DC-AC converter as a function of solar irradiation and temperature level.

The results show that the reactive power is set to zero, the grid voltage is kept constant, and the measured grid current and active power follow the irradiation and temperature variations.

(a)

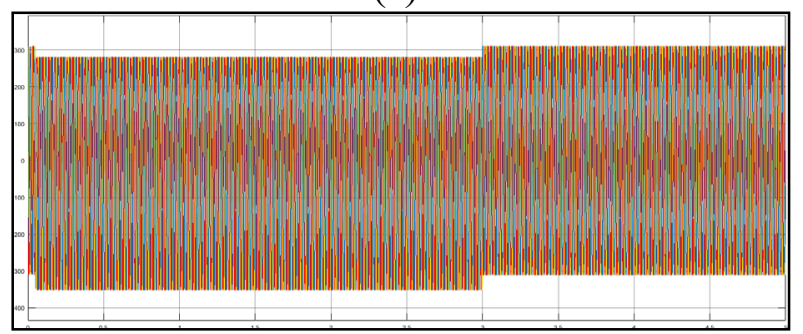

(b)

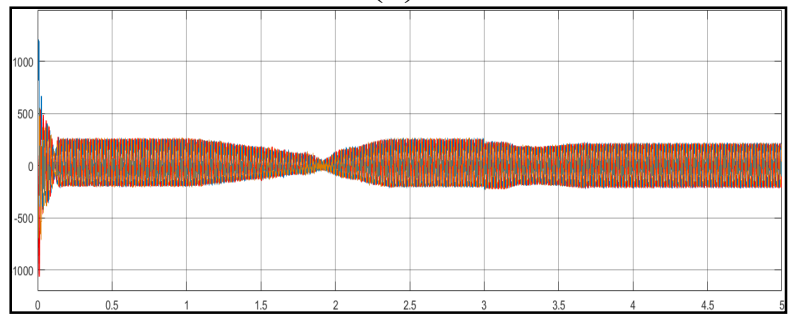

(c)

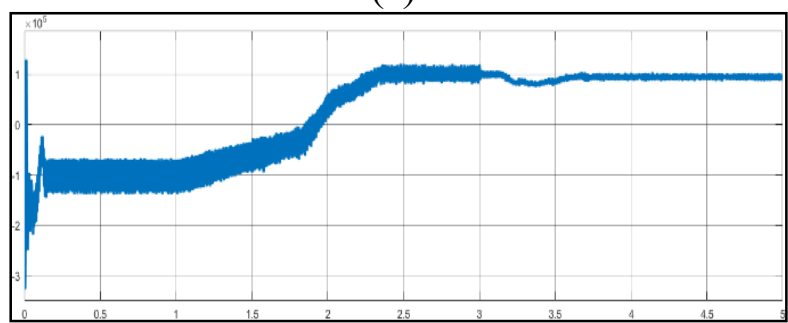

(d)

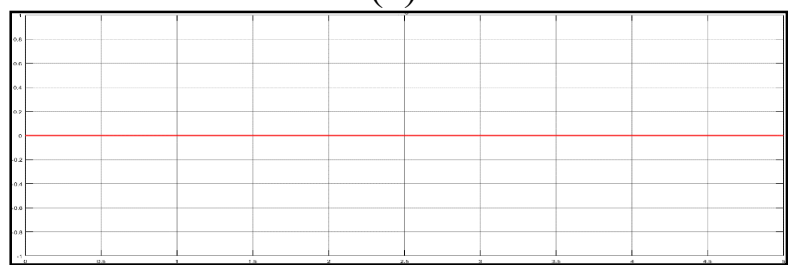

Fig. 10. (a) Grid side voltage, (b) current, (c) active and (d) reactive powers of the DC-AC converter with variable solar irradiation and temperature level.

\section{Conclusion}

A multi-source system is studied in this paper. Models and control schemes are provided for all converters to maintain stable system operation under various irradiation and temperature conditions. The control strategy is verified by Matlab/Simulink. The simulation results show that the multi-source system can operate stably under changing climatic conditions. The stability of the mains and DC bus voltage can be guaranteed when operating conditions change. 


\section{References}

1. http://www.abhatoo.net.ma/maalama-

textuelle/developpement-economique-et-

social/developpement-economique/energie-et-

mines/politique-energetique/strategie-energetiquenationale-horizon-2030

2. https://www.solarthermalworld.org/sites/default/fil es/news/file/2019-10

$\underline{08 / \text { strategie energetique nationale maroc 2030.p }}$ df

3. I. Gyuk et al., "Grid Energy Storage," United States Dep. Energy, no. December, p. 67, 2013.

4. H. Ibrahim and A. Ilinc, "Techno-Economic Analysis of Different Energy Storage Technologies," Energy Storage - Technol. Appl., pp. 1-40, 2013.

5. C. A. Hill, M. C. Such, D. Chen, J. Gonzalez, and W. M. K. Grady, "Battery energy storage for enabling integration of distributed solar power generation," IEEE Trans. Smart Grid, vol. 3, no. 2, pp. 850-857, 2012.

6. U. Manandhar et al., "Energy Management and Control for Grid Connected Hybrid Energy Storage System under Different Operating Modes," IEEE Trans. Smart Grid, vol. 3053, no. c, pp. 1-11, 2017.

7. S. Sholapur, K. R. Mohan, and T. R. Narsimhegowda, "Boost Converter Topology for PV System with Perturb And Observe MPPT Algorithm," IOSR J. Electr. Electron. Eng., vol. 9, no. 4, pp. 50-56, 2014.

8. S. Umashankar, K. P. Aparna, R. Priya, and S. Suryanarayanan, "Modeling and Simulation of a PV System using DC-DC Converter," Int. J. Latest Res. Eng. Technol., vol. 1, no. 2, pp. 9-16, 2015.

9. C. Carrero, J. Amador, and S. Arnaltes, "A single procedure for helping PV designers to select silicon PV modules and evaluate the loss resistances," Renew. Energy, vol. 32, no. 15, pp. 2579-2589, 2007.

10. H. J. Kim, Y. Cho, J. Kim, J. Cho, and J. Kim, "Demonstration of the LVDC distribution system in an island," CIRED - Open Access Proc. J., vol. 2017, no. 1, pp. 2215-2218, 2017.

11. S. Pg, M. E. Control, and N. Maharashtra, "Perturb and Observe Based Mppt for Solar Power Generation,” pp. 1820-1825, 2017.

12. X. Cai, B. Fu, Y. Huang, X. Xing, L. Yu, and N. Yi, "A Research of MPPT Implementation Strategy Based on the Improved Conductance Increment Method," no. 1, pp. 1-4.

13. B. Subudhi and R. Pradhan, "A Comparative Study on Maximum Power Point Tracking Techniques for Photovoltaic Power Systems," Sustain. Energy, IEEE Trans., vol. 4, no. 1, pp. 89-98, 2013. 